\title{
PEMODELAN GRAPH DATABASE UNTUK MODA TRANSPORTASI BUS RAPID TRANSIT
}

\author{
Panji Wisnu Wirawan $^{1}$, Djalal Er Riyanto ${ }^{2}$, Khadijah $^{3}$ \\ Departemen Ilmu Komputer/Informatika, Fakultas Sains dan Matematika,Unversitas \\ Diponegoro \\ J1. Prof Soedarto, SH, Tembalang, Semarang, (024)747 4754 \\ Email :maspanji@undip.ac.id ${ }^{1}$,erriyanto@undip.ac.id ${ }^{2}$,khadijah0303@gmail.com³
}

\begin{abstract}
Abstrak
Bus Rapid Transit (BRT) merupakan salah satu alternatif transportasi massal. Rute BRT memiliki karakteristik khusus yang dapat dimodelkan dengan graph. Ketika rute dan shelter semakin bertambah, dibutuhkan aplikasi komputer untuk melakukan pencarian rute BRT. Hal tersebut akan memudahkan pencarian dan penjelajahan rute-rute BRT. Namun, ketika rute diimplementasikan menggunakan basis data relasional, performa query dapat menurun karena banyaknya operasi JOIN untuk mencari rute. Artikel ini mengusulkan sebuah model graph database untuk BRT dan implementasinya. Identifikasi kebutuhan data dilakukan, dilanjutkan dengan pemodelan menggunakan entity relationship (ER). Hasil ER tersebut kemudian dipetakan ke dalam property graph untuk kemudian diimplementasikan menggunakan produk graph database Neo4J. Hasil penelitian ini menunjukkan bahwa model yang dibuat bisa diterapkan dalam basis data graph dan graph dapat menunjukkan rute BRT tertentu. Dari sisi performance, basis data graph menunjukkan kinerja perambatan yang lebih baik dibandingkan dengan basis data relasional.
\end{abstract}

Keyword : BRT, graphdatabase

\section{PENDAHULUAN}

Masyarakat di beberapa kota di Indonesia saat ini telah memiliki alternatif transportasi massal yang dinamakan dengan Bus Rapid Transit (BRT). BRT hadir dengan berbagai nama seperti Trans Jakarta (Jakarta), Trans Semarang (Semarang), Trans Jogja (Yogyakarta), Batik Solo Trans (Solo), Trans Musi (Palembang) dan yang lainnya. Hadirnya BRT merupakan upaya untuk menyediakan transportasi yang dapat menambah penggunaan transportasi umum, menambah tingkat dan kualitas layanan transportasi publik (Mzee \& Chen, 2010).

Sistem BRT di Indonesia memiliki shelter / halte tertentu. Shelter tersebut memiliki beberapa tipe, misalnya transit point dan transfer point. Selain itu, setiap bus pada BRT memiliki ruterute perjalanan tertentu yang biasanya disebut dengan koridor, di mana setiap bus melewati shelter yang telah ditentukan. Dengan demikian BRT merupakan sebuah jaringan transportasi. Pemodelan data terkait dengan jaringan transportasi ini penting ketika akan membuat sebuah program/aplikasi komputer.

Basis data relasional telah lama menjadi standar penyimpanan data pada program/aplikasi komputer. Dalam basis data relasional, data disimpan dalam tabel dan kolom di mana antar tabel dapat saling dikaitkan melalui kunci. Apabila diinginkan data dari tabel yang berbeda, dilakukan permintaan (query) menggunakan klausa JOIN. Untuk jaringan transportasi, jika disimpan dalam basis data relasional, akan memerlukan banyak operasi JOIN query yang menyebabkan komputasi tinggi (Dominguez-Sal et al., 2010). Dengan demikian performa aplikasi dapat menurun.

Graphdatabase dapat menjadi solusi alternatif untuk menyimpan data jaringan transportasi. Hal tersebut disebabkan karena graphdatabase menyimpan data seperti halnya graph, yaitu dalam node-node yang berhubungan satu sama lain. Artinya, analisis jaringan transportasi dapat 
memanfaatkan operasi graph seperti menemukan daerah sekitar (neighbourhood), penjelajahan (traversal) jalur transportasi, serta menemukan lintasan terpendek (Dominguez-Sal et al., 2010). Artikel ini mengusulkan sebuah model dari graphdatabase yang dapat dimanfaatkan untuk jaringan transportasi Bus Rapid Transit. Disertakan pula contoh implementasi dari graphdatabase tersebut menggunakan salah satu produk graphdatabase yaitu Neo4J (Neo4J, n.d.). Diharapkan dari model tersebut, dapat berkontribusi dalam memudahkan pengembangan program/aplikasi yang membutuhkan penyimpanan data jaringan transportasi menggunakan GDB.

\section{TINJAUAN PUSTAKA}

\subsection{GRAPH}

Graph adalah konsep matematika untuk menyajikan suatu himpunan objek, di mana pasangan dari objek terhubung dengan suatu penghubung (link). Suatu graph berarah $G=(\mathrm{V}, \mathrm{E})$ didefinisikan sebagai suatu himpunan node $\mathrm{V}$ dan himpunan edge $\mathrm{E}$ dengan ukuran $\mathrm{m}$. Setiap edge terhubung ke dua node, satu node sebagai sumber dan yang lainnya sebagai target. Tergantung pada skenario yang disiapkan, suatu edge dapat memiliki beberapa atribut tambahan. Biasanya, suatu edge e $€ \mathrm{E}$ secara unik diidentifikasi oleh sumbernya yaitu $\mathrm{u} € \mathrm{~V}$ dan target dari $\mathrm{v} € \mathrm{~V}$. Dalam hal terdapat edge paralel dengan sumber dan target yang sama, atribut tambahan dari suatu edge atau konteks diperlukan untuk suatu identifikasi unik.

Suatu path $\mathrm{P}$ di dalam $\mathrm{G}$ ialah suatu urutan edge $\left(\mathrm{e}_{1}, \ldots, \mathrm{e}_{\mathrm{k}}\right)$, sedemikian rupa sehingga target dari $\mathrm{e}_{\mathrm{i}}$ dan sumber dari $\mathrm{e}_{\mathrm{i}+1}$ adalah sama untuk semua $1 \leq \mathrm{i} \leq(\mathrm{k}-1)$. Dalam hal graph tidak mempunyai edge paralel atau jika bebas dari konteks, dapat pula disajikan urutan node $\left(\mathrm{u}_{1}, \ldots\right.$, $\mathrm{u}_{\mathrm{k}}, \mathrm{u}_{\mathrm{k}+1}$ ), di mana $\mathrm{u}_{\mathrm{i}}$ adalah sumber dari edge $\mathrm{e}_{\mathrm{i}}$, untuk semua $1 \leq \mathrm{i} \leq \mathrm{k}$, dan $\mathrm{u}_{\mathrm{k}+1}$ adalah target dari $\mathrm{e}_{\mathrm{k}}$. Dalam hal ini $\mathrm{u}_{1}$ adalah sumber dari $\mathrm{P}$ dan $\mathrm{u}_{\mathrm{k}+1}$ adalah target dari $\mathrm{P}$.

Graph database memodelkan data sebagai data yang saling terhubung. Tidak seperti basis data relasional yang menyimpan data dalam tabel-tabel, basis data graf menyimpan data dalam bentuk nodes dan hubungan antar datanya menggunakan edges. Setiap node, secara internal, memiliki pointer ke node yang lain ataupun ke subgraf (Celko, 2014).

Graph database adalah suatu sistem manajemen basis data online dengan metoda Create, Read, Update dan Delete (CRUD) yang menampakkan mode data graph. Basis data ini dibangun dengan menggunakan sistem Online Transaction Processing (OLTP), sehingga akan memenuhi transactional integrity dan availability.

Query dengan banyak join (joint-intensive) pada database relasional akan menurunkan kinerja khususnya untuk data yang bervolume besar. Akan tetapi, kinerja graphdatabase cenderung tetap relative konstan, meskipun terjadi pertumbuhan atau peningkatan data. Hal ini disebabkan karena pada umumnya query terbatas pada suatu segment dari graph. Waktu eksekusi untuk setiap query hanya proporsional ke ukuran dari segmentgraph yang terkait dengan query dan tidak dengan ukuran totalnya.

Pada sembarang kesempatan dapat dilakukan penambahan node dan relationship baru ke dalam model graph. Penambahan node dan relationship ke struktur yang sekarang ada tidak akan mengganggu fungsi query dan fungsi aplikasi.

\subsection{GRAPH DATA MODEL}

Model merupakan representasi konseptual dari sesuatu yang akan dibangun/dilaksanakan. Sehingga dengan menggunakan model, apa yang akan dibangun/dilaksanakan diharapkan dapat dikomunikasikan dengan baik. Dari sudut pandang database, setidaknya model dapat menggambarkan struktur data, deskripsi, maintenance, dan bagaimana memperoleh data tersebut (Angles \& Gutierrez, 2008).

Angles \& Gutierrez (2008), melakukan kajian mengenai graph data model. Beberapa model dikaji dan salah satunya adalah GDM (Graph Data Model). GDM merupakan data model untuk graph yang diusulkan oleh Hidders (2003). Dalam model tersebut, terdapat instance graphs dan schema graphs. Hidders (2003) juga memperkenalkan dua operasi manipulasi graph, yaitu pendambahan dan penghapusan. 
Pada GDM, instance graph merupakan graph berlabel dimana node menggambarkan entitas, sedangkan edges mencerminkan atribut untuk setiap entitas. Node-node yang dimiliki oleh beberapa class, diberi label dari nama kelas yang memilikinya. Lain halnya dengan Schema graphs, node pada schema graphs menggambarkan class sedangkan edge yang diberi label dengan nama atribut menandakan bahwa entitas dari class memiliki atribut tersebut. Konsep data model yang diberikan pada GDM masih mengadopsi dari konsep berorientasi objek seperti class, instance, dan inheritance.

Pendekatan data model graph yang lain dilakukan oleh De Virgilio, Maccioni, \& Torlone, (2014). Model graph dibentuk dengan terlebih dahulu membentuk Entity Relationship Diagram (ERD). ERD kemudian ditransformasikan menjadi model graph, yang disebut property graph. Propertygraph merupakan merupakan 'multigraph' dimana node maupun edge diberi label dengan data yang merupakan pasangan kunci-nilai (key-value pair).

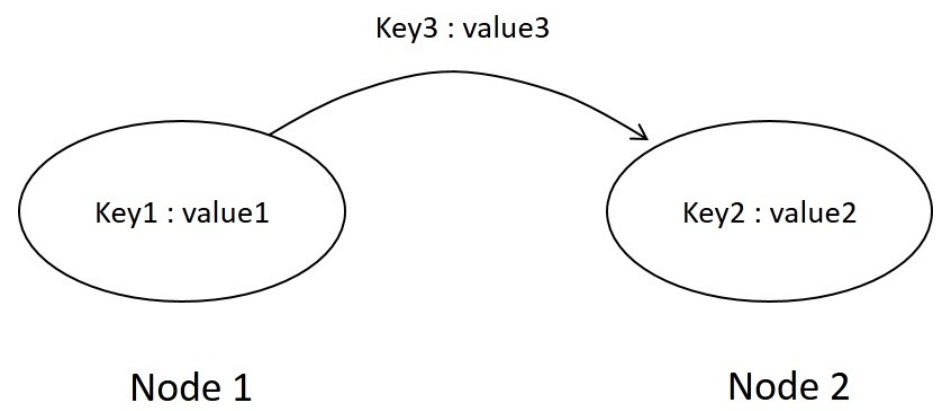

Gambar 1. Property graph

Lebih lanjut, De Virgilio et al. (2014) memberikan panduan untuk transformasi ERD menjadi model graph sebagai berikut :

a. Relasi one-to-one bertransformasi menjadi graph dengan edge memiliki dua arah (double directed)

b. Relasi one-to-many bertransformasi menjadi graph dengan edge memiliki satu arah, dari entitas berkardinalitas rendah ke tinggi.

c. Relasi many-to-many bertransformasi menjadi graph dengan edge dua arah (double directed) dengan bobot yang berbeda dengan relasi one-to-one.

\section{METODE PENELITIAN}

Penelitian ini menggunakan beberapa tahapan dalam membentuk model graphdatabase sebagai berikut :

1. Identifikasi kebutuhan data.

Pada tahap ini dilakukan identifikasi data yang diperlukan untuk membentuk sebuah rute bus rapid transit. Sebagai studi kasus, dipilih rute pada Bus Rapid Transit

Semarang.

2. Pemodelan graphdatabase.

Berdasarkan kebuthan data yang telah diidentifikasikan, dibuatlah model

graphdatabase. Model yang dipilih adalah model yang dikemukakan oleh De Virgilio et al. (2014).

3. Implementasi model.

Neo4J akan digunakan sebagai graphdatabase untuk mengimplementasikan model yang telah dikembangkan.

\section{HASIL DAN PEMBAHASAN}

4.1.KEBUTUHAN DATA 
Identifikasi kebutuhan data diperlukan untuk mendapatkan pemodelan data yang tepat. Pada bagian ini, akan diidentifikasi kebutuhan data yang diperlukan untuk rute Bus Rapid Transit. Sebagai studi kasus, dipilih Bus Rapid Transit Semarang.

BRT memiliki rute berbasis koridor atau jalur-jalur yang dilewati. Rute BRT Trans Semarang mencakup empat koridor. Sepanjang rute terdapat sejumlah tempat pemberhentian bus yang disebut dengan shelter. Terdapat dua jenis shelter, yaitu: a) sheltertransit point, dan b) sheltertransfer point. Kedua shelter tersebut mempunyai fungsi utama yang sama, yaitu untuk tempat menurunkan atau menaikkan penumpang.

Sheltertransfer point digunakan untuk menaikkan dan menurunkan penumpang yang berasal dan atau mempunyai tujuan yang sesuai dengan rute BRT yang dinaiki. Sedangkan untuk sheltertransit point, titik lokasi shelter berada pada lokasi yang memungkinkan penumpang meneruskan perjalanan ke rute lain yang di luar rute BRT, atau pindah ke moda angkutan lain (bus umum, pesawat udara, kereta api, kapal laut).

Berdasarkan informasi tersebut, maka dapat ditentukan data yang diperlukan untuk rute BRT yaitu:

(a) Shelter sebagai node; dan

(b) Jalur penghubung shelter sebagai edge, yang merupakan bagian dari suatu koridor.

\subsection{PEMODELAN GRAPH DATABASE UNTUK BRT}

Graphdatabase disusun dari node dan relationship. Baik node maupun relationship, dapat memiliki satu atau lebih atribut yang dapat menjelaskan mengenai node atau relationship tersebut. Dalam konteks BRT Semarang, pembentukan node dan relationship berikut :

a. Shelter dapat dimodelkan menggunakan Node. Hal ini dapat dilakukan karena shelter merupakan titik dimana BRT berhenti untuk menurunkan atau menaikkan penumpang. Masing-masing shelter BRT terletak di lokasi tertentu (memiliki nama), dan memiliki tipe shelter tersendiri yaitu sebagai shelter transfer point ataupun shelter transit point.

b. Koridor dapat dimodelkan dengan Relationship. Relationship yang menghubungkan antar node bisa digunakan untuk mengasosiasikan hubungan antara shelter-shelter yang terhubung menggunakan koridor bus BRT yang ada. Setiap koridor memiliki nama yang menunjukkan rute BRT.

Secara ringkas, data beserta property untuk masing masing shelter dan relationship ditunjukkan tabel 1 .

Tabel 1. Node dan property pada graphdatabase

\begin{tabular}{|l|l|l|}
\hline \multicolumn{1}{|c|}{ Data } & \multicolumn{1}{|c|}{ Tipe } & \multicolumn{1}{c|}{ Property } \\
\hline $\begin{array}{l}\text { ShelterTransit } \\
\text { point }\end{array}$ & Node & $\begin{array}{l}\text { SID } \text { (shelter } \text { ID) } \\
\text { Nama Shelter }\end{array}$ \\
$\begin{array}{l}\text { ShelterTransfer } \\
\text { point }\end{array}$ & Node & $\begin{array}{l}\text { SID } \text { (shelter } \text { ID) } \\
\text { Nama Shelter }\end{array}$ \\
\hline Koridor & Relationship & Nama koridor \\
\hline
\end{tabular}

Dari sisi pemodelan ERD, terdapat dua buah entitas yaitu sheltertransit point dan sheltertransfer point. Sedangkan koridor akan menjadi relationship. Relationship menghubungan antara satu node (shelter) dengan node yang lain. Node yang merupakan transit point terhubung dengan satu transit point yang lain. Sedangkan untuk transfer point, dapat terhubung dengan lebih dari transit point. Sehingga hubungan ERD yang tepat untuk sheltertransit point dan sheltertransfer point adalah one-to-many. Untuk hubungan antar transit point adalah one-to-one. 


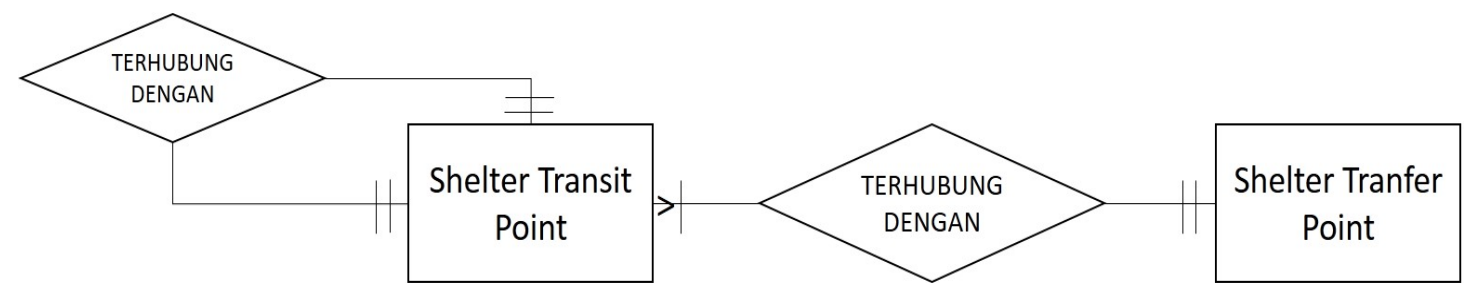

Gambar 2. ERD untuk BRT

Selanjutnya, ERD yang dihasilkan digunakan untuk membentuk model propertygraph. Akan terdapat dua node yaitu sheltertransit point dan sheltertransfer point. Transit point dengan transfer point memiliki hubungan many-to-one sehingga hubungan antar keduanya memiliki dua arah (bidirectional). Antar transit point memiliki hubungan dengan satu transit point yang lain dan searah sehingga antar transit point memiliki hubungan satu arah (uni directional).

Property dari masing-masing node dan relationship kemudian ditempatkan pada posisinya masing-masing. Sehingga didapatkan propertygraph seperti pada gambar 3.

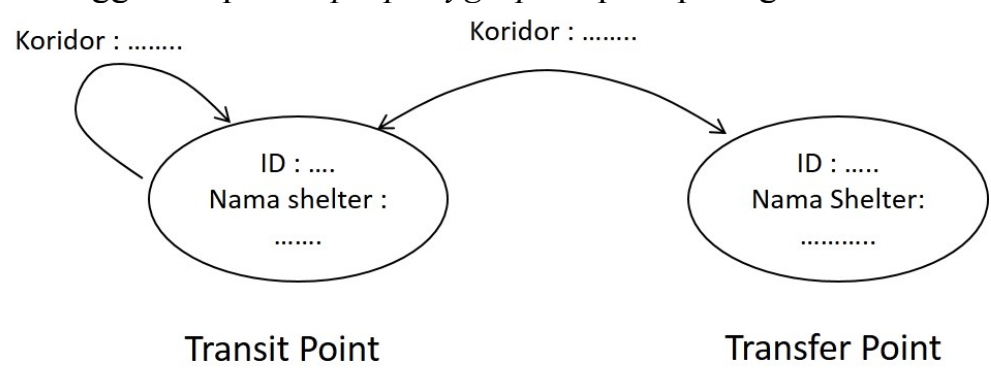

Gambar 3. Hasil model graphdatabase untuk BRT

Berikutnya, propertygraph tersebut akan diimplementasikan dalam sebuah graphdatabase, untuk membuktikan bahwa model tersebut telah sesuai dengan kebutuhan.

\subsection{IMPLEMENTASI MODEL}

Model gambar 3 diimplementasikan menggunakan graphdatabase Neo4J dengan mengambil data pada semua koridor BRT TransSemarang, yaitu koridor I, II, IIIA,IIIb dan koridor IV. Secara keseluruhan terdapat 206 shelter, yang terdiri dari 16 sheltertransit point dan 190 sheltertransfer point. Masing-masing memiliki nama shelter yang dapat digunakan sebagai data pada propertygraph.

Neo4j memiliki query yang disebut Cypher query. Query tersebut selanjutnya akan digunakan untuk membentuk transfer maupun transit point. Query Q1 dan Q2 adalah contoh cypher query yang berturut-turut digunakan untuk membentuk transfer point dan transit point. Query Q1 merupakan pembentukan node dengan label TransferPoint dan shelter id (sid) 1 dan nama shelter Balai Kota. Query Q2 akan membentuk node dengan label TransitPoint dan shelter id 10 dan nama shelter Pekunden. Query Q1 dan Q2 diulang untuk setiap shelter yang bersesuaian sehingga terbentuklah node-node yang diperlukan pada semua koridor.

Q1 : membentuk transit point

CREATE (s: shelter:TransitPoint\{sid:1, nama_shelter:"Balai Kota" \}) RETURN shelter

Q2: membentuk transfer point

CREATE (s:shelter:TransferPoint\{sid:10, nama_shelter:"Pekunden" \}) RETURN shelter 
Ketika node-node telah terbentuk, langkah selanjutnya adalah membentuk relationship untuk setiap node. Query Q3 merupakan query untuk membentuk relationship antar node. Query tersebut membentuk relationship antara shelter Pandanaran 2 dan Pekunden. Karena antara Pandanaran 2 dan Pekunden merupakan sheltertransfer point, maka arah graph pada query tersebut adalah searah, dari dari Pandanaran 2 ke Pekunden.

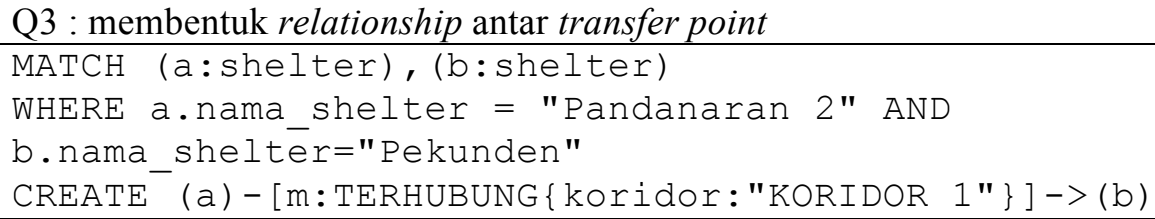

Query Q3 bekerja dengan cara menemukan shelter dengan nama Pandaranan 2 dan Pekunden, memberikan label jika ditemukan, kemudian membuat relationship antara keduanya. Relasi antara keduanya adalah TERHUBUNG dengan property koridor dengan data KORIDOR 1.

Koridor 1 pada BRT Trans Semarang melewati 75 shelter, yang terdiri dari 9 sheltertransit point dan 66 sheltertransfer point. Masing-masing shelter dibentuk dengan query Q1 dan Q2 dan hubungan antar shelter dibuat menggunakan Q3. Hasil dari query-query yang telah diimplementasikan pada Neo4J untuk koridor 1, ditunjukkan pada gambar 4.

Gambar 4 merupakan hasil visualisasi yang dilakukan oleh Neo4J, tidak menunjukkan posisi shelter pada posisi sebenarnya. Pada gambar 4, node (ditunjukkan dengan lingkaran) dengan warna hitam merupakan transit point sedangkan node dengan warna putih merupakan transfer point. Jalur yang menghubungan shelter (edge) ditunjukkan dengan garis yang memiliki arah. Visualisasi tersebut menunjukkan bahwa model yang dihasilkan dari penelitian ini dapat membentuk shelter dan jalur antar shelter sedemikian hingga membentuk sebuah koridor atau rute perjalanan BRT. 


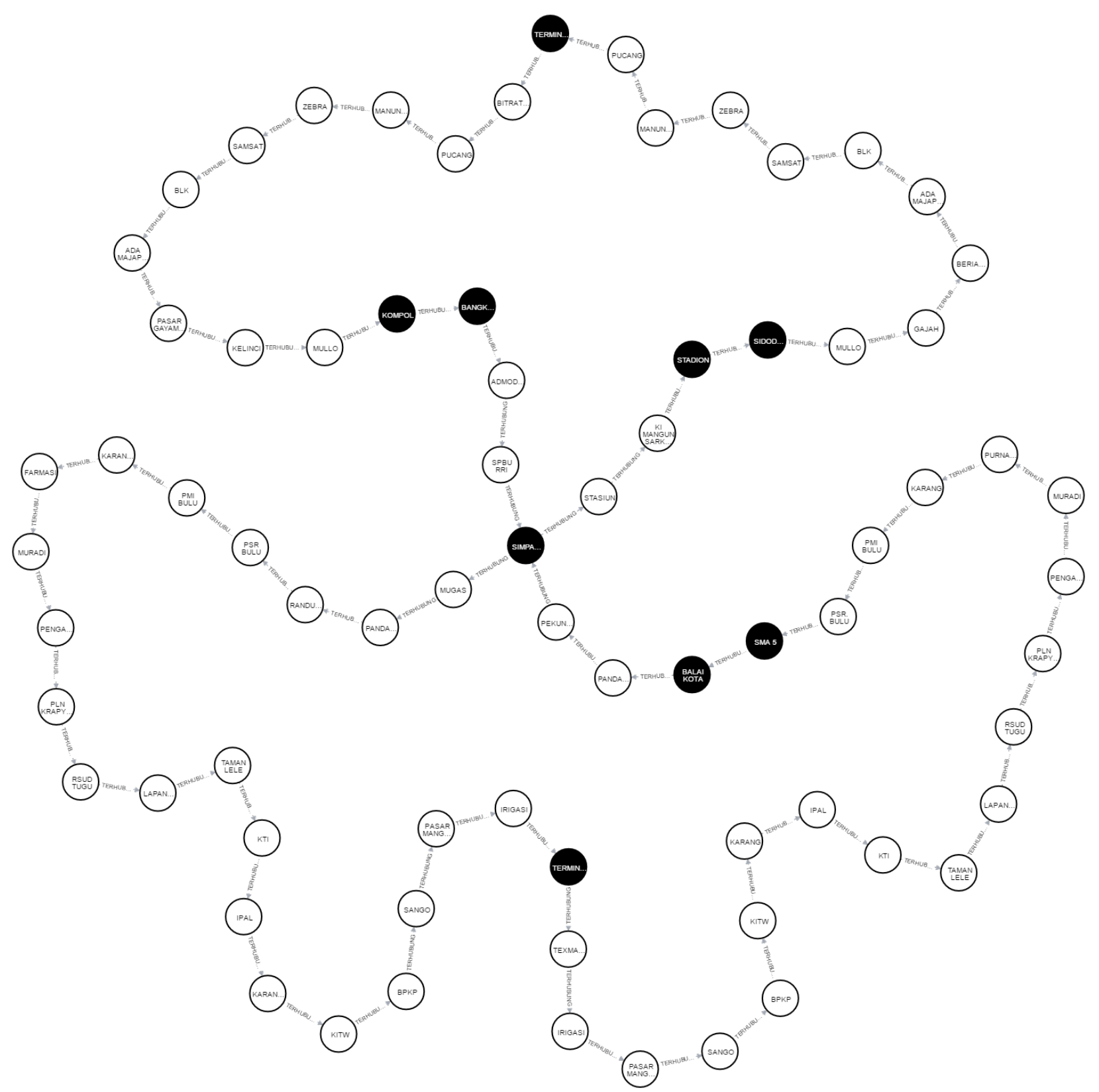

Gambar 4. Hasil implementasi pada Neo4J pada koridor 1. 


\subsection{PENGUJIAN PERFORMA}

Pengujian performa dilakukan untuk mengetahui seberapa cepat respon graph database dalam melakukan proses perambatan (traversing) shelter. Sebagai pembanding, model dari data rute bus TransSemarang diimplementasikan pula pada sistem pengelolaan basis data relasional MySQL, berpedoman pada gambar 2.

Pengujian dilakukan dengan mengakses kedua data, yaitu pada MySQL dan Neo4J, menggunakan program Java dengan driver standar (official) untuk masing-masing sistem pengelolaan basis data MySQL dan Neo4J. Akses data dilakukan untuk melakukan perambatan 18 node pada koridor IV, dimulai dari terminal Cangkiran. Pengukuran waktu permintaan (query) dimulai dari ketika program memulai permintaan sampai dengan menutup koneksi basis data. Satuan waktu yang digunakan dalam pengujian ini adalah dalam nano detik. Hasil pengujian ditunjukkan pada gambar 5 .

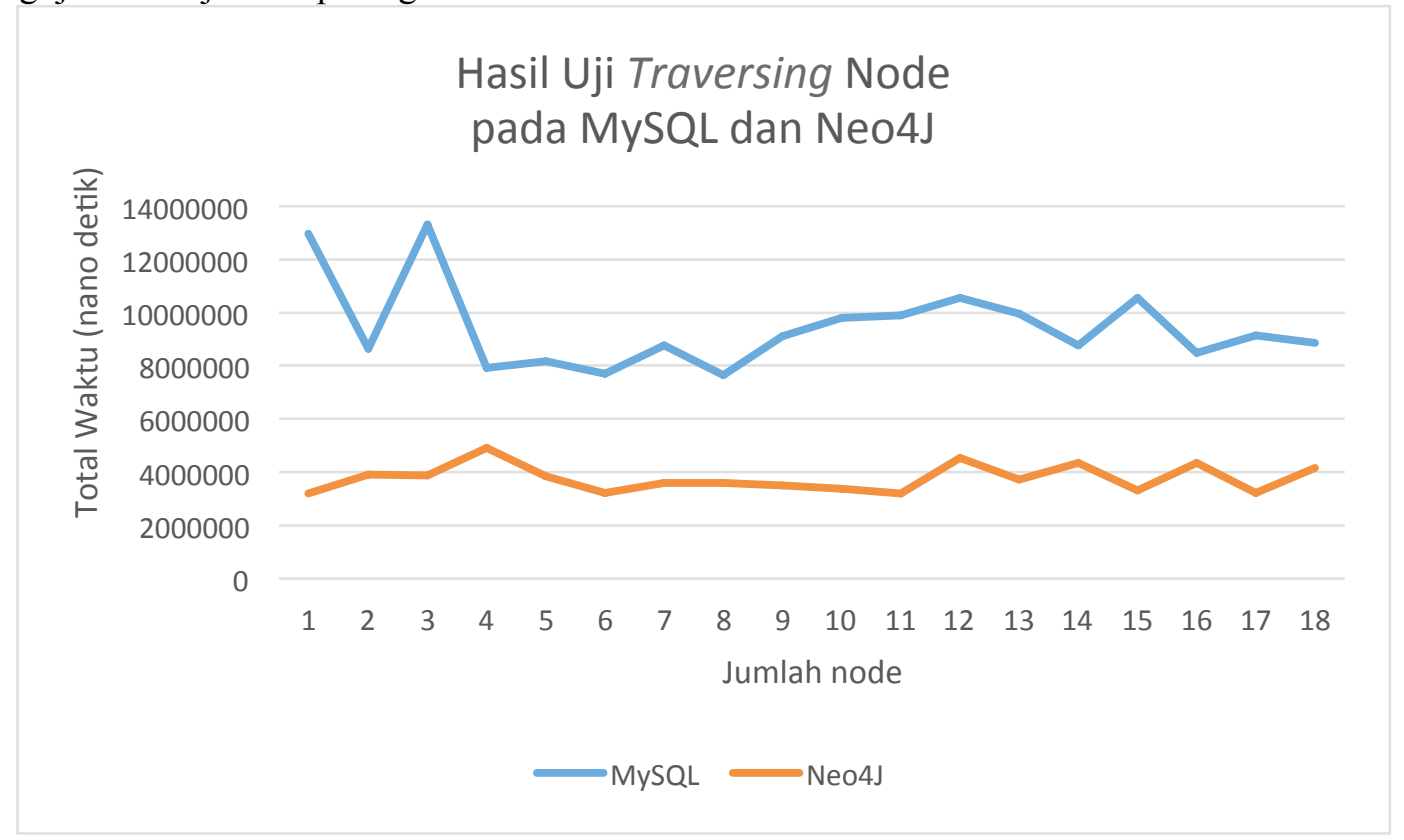

Gambar 5. Hasil uji tranversing node pada koridor IV.

Gambar 5 menunjukkan bahwa untuk setiap jumlah node yang diuji, MySQL memiliki waktu permintaan (query) untuk perambatan node yang lebih lama dibandingkan dengan Neo4J. Hasil tersebut menunjukkan pula bahwa untuk data yang memerlukan proses perambatan seperti pada data transportasi, lebih tepat ketika basis data yang digunakan adalah basis data dengan model data graph.

\section{KESIMPULAN}

Model graphdatabase dapat dibuat untuk BRT menggunakan propertygraph. Hasil penelitian ini menunjukkan bahwa untuk studi kasus BRT TransSemarang, model graph yang dihasilkan adalah adanya node yang merupakan sheltertransit point dan sheltertransfer point pada model yang dihasilkan. Satu sheltertransit point terhubung dengan satu sheltertransit point yang lain, sedangkan satu sheltertransfer point dapat terhubung dengan banyak sheltertransit point. Model yang dibuat kemudian dapat diimplementasikan menggunakan basis data graph Neo4J. Hasil pengujian menunjukkan bahwa performa basis data graph untuk masalah perambatan (traversing) menunjukkan hasil yang lebih baik daripada menggunakan basis data relasional. 


\section{DAFTAR PUSTAKA}

Angles, R., \& Gutierrez, C. (2008). Survey of graphdatabase models. ACM Computing Surveys, 40(1), 1-39. http://doi.org/10.1145/1322432.1322433

Celko, J. (2014). NoSQL and Transaction Processing. In Joe Celko's Complete Guide to NoSQL (pp. 1-14). Elsevier. http://doi.org/10.1016/B978-0-12-407192-6.00001-7

De Virgilio, R., Maccioni, A., \& Torlone, R. (2014). Model-Driven Design of GraphDatabases (pp. 172-185). http://doi.org/10.1007/978-3-319-12206-9_14

Dominguez-Sal, D., Urbón-Bayes, P., Giménez-Vañó, A., Gómez-Villamor, S., MartínezBazán, N., \& Larriba-Pey, J. L. (2010). Survey of GraphDatabase Performance on the HPC Scalable Graph Analysis Benchmark (pp. 37-48). http://doi.org/10.1007/978-3-642$16720-14$

Hidders, J. (2003). Typing Graph-Manipulation Operations. In Database Theory --- ICDT 2003: 9th International Conference Siena, Italy, January 8--10, 2003 Proceedings (pp. 394-409). http://doi.org/10.1007/3-540-36285-1_26

Mzee, P. K., \& Chen, Y. (2010). Implementation of Bus Rapid Transit System as an Alternative for Public Transportation in Developing Countries Case of Dart System in Dar Es Salaam. In 2010 International Conference on Intelligent Computation Technology and Automation (pp. 489-493). IEEE. http://doi.org/10.1109/ICICTA.2010.233

Neo4J. (n.d.). Neo4J : The World's Leading GraphDatabase. Retrieved from http://neo4j.com 